Corrigendum

\title{
Corrigendum to "Prevalence of APOL1 Risk Variants in Afro-Descendant Patients with Chronic Kidney Disease in a Latin American Country"
}

\author{
Carlos E. Duran $\mathbb{D}^{1},{ }^{1}$ Alejandro Ramírez $\mathbb{D},{ }^{2}$ Juan G. Posada, ${ }^{1}$ Johanna Schweineberg, ${ }^{1}$ \\ Liliana Mesa, ${ }^{1}$ Harry Pachajoa, ${ }^{3}$ Mayra Estacio $\left(D,{ }^{4}\right.$ Eliana Manzi, ${ }^{4}$ Vanessa Aros, ${ }^{4}$ \\ Lorena Díaz, ${ }^{3}$ and Victor H. Garcia ${ }^{4}$ \\ ${ }^{1}$ Department of Nephrology, Fundacion Valle del Lili, Cali, Colombia \\ ${ }^{2}$ Health Sciences Faculty, Icesi University, Cali, Colombia \\ ${ }^{3}$ Department of Basic Medical Sciences, Center for Research on Congenital Anomalies and Rare Diseases (CIACER), \\ Universidad Icesi, Cali, Colombia \\ ${ }^{4}$ Clinical Research Center, Fundación Valle del Lili, Cali, Colombia
}

Correspondence should be addressed to Carlos E. Duran; carlosed36@gmail.com

Received 1 November 2020; Accepted 1 November 2020; Published 21 November 2020

Copyright (c) 2020 Carlos E. Duran et al. This is an open access article distributed under the Creative Commons Attribution License, which permits unrestricted use, distribution, and reproduction in any medium, provided the original work is properly cited.

In the article titled "Prevalence of APOL1 Risk Variants in Afro-Descendant Patients with Chronic Kidney Disease in a Latin American Country" [1], the authors Harry Pachajoa and Lorena Diaz were affiliated to Department of Basic Medical Sciences, Center for Research on Congenital Anomalies and Rare Diseases (CIACER), Icesi University, Cali, Colombia, which is incorrect. The correct affiliation for the authors Harry Pachajoa and Lorena Diaz is Department of Basic Medical Sciences, Center for Research on Congenital Anomalies and Rare Diseases (CIACER), Universidad Icesi, Cali, Colombia, which is listed above.

\section{References}

[1] C. E. Duran, A. Ramírez, J. G. Posada et al., "Prevalence of APOL1 risk variants in afro-descendant patients with chronic kidney disease in a Latin American country," International Journal of Nephrology, vol. 2019, Article ID 7076326, 5 pages, 2019. 